\title{
When Parity Promotes Peace: Resolving Conflict Between Asymmetric Agents
}

\author{
Erik O. Kimbrough ${ }^{\text {a }}$ \\ Roman M. Sheremeta ${ }^{b}$ \\ Timothy W. Shields ${ }^{c}$ \\ ${ }^{a}$ Department of Economics, Simon Fraser University, \\ 8888 University Drive, Burnaby, BC V5A 1S6, Canada \\ ${ }^{\mathrm{b}}$ Weatherhead School of Management, Case Western Reserve University \\ and the Economic Science Institute, Chapman University \\ 11119 Bellflower Road, Cleveland, OH 44106, U.S.A. \\ c Argyros School of Business and Economics, Chapman University, \\ One University Drive, Orange, CA 92866, USA
}

December 20, 2013

\begin{abstract}
Due to the high costs of conflict both in theory and practice, we examine and experimentally test the conditions under which conflict between asymmetric agents can be resolved. We model conflict as a two-agent rent-seeking contest for an indivisible prize. Before conflict arises, both agents may agree to allocate the prize by fair coin flip to avoid the costs of conflict. The model predicts that "parity promotes peace": in the pure-strategy equilibrium, agents with relatively symmetric conflict capabilities agree to resolve the conflict by using a random device; however, with sufficiently asymmetric capabilities, conflicts are unavoidable because the stronger agent prefers to fight. The results of the experiment confirm that the availability of the random device partially eliminates conflicts when agents are relatively symmetric; however, the device also reduces conflict between substantially asymmetric agents.
\end{abstract}

JEL Classifications: C72, C91, D72, D74

Keywords: contest, asymmetries, conflict resolution, experiments

Corresponding author: Roman M. Sheremeta, rms246@case.edu

The earlier version of this paper circulated under the title "Resolving Conflicts by a Random Device." The authors thank the Economic Science Institute at Chapman University for financial support. The authors thank the Associate Editor and two anonymous referees for thoughtful and constructive comments. The authors also thank Larry Iannaccone, Kai Konrad, Florian Morath, Jared Rubin and economic seminar participants at the Economic Science Institute at Chapman University and the Max Planck Institute in Munich, as well as participants at the 2011 Economic Science Association Conference in Tucson, Southwest Economic Theory Conference in Honolulu, and Tournaments, Contests and Relative Performance Conference in Fresno for insightful comments. 


\title{
1. Introduction
}

\author{
"Justice originates among those who are approximately equally powerful (...) \\ where there is no clearly recognizable predominance and a fight would mean \\ inconclusive mutual damage (...)"
}

(Friedrich Nietzsche, Human, All Too Human, Section 92)

In the opening quote, Nietzsche contends that peace and justice are most easily negotiated when the costs of conflict are highest, or when opponents are evenly matched. In this paper, we develop a model formalizing Nietzsche's intuition, and we test the predictions of the model in a laboratory experiment in which two individuals bargain to avoid conflict over a valuable resource. We model conflict as a variation of the classic Tullock (1980) rent-seeking contest between two agents. In our setup, two agents face the prospect of conflict over an indivisible prize. Before conflict arises both participants may agree to settle the dispute via a simple conflict resolution mechanism (a fair coin flip) and thereby avoid the costs of the contest. We assume that individuals can credibly commit to the outcome of the random device. ${ }^{1}$ The model predicts that "parity promotes peace": if agents are relatively symmetric, then conflicts can be avoided through appeals to the random device (consistent with Nietzsche's conjecture); however, when agents are substantially asymmetric, then conflicts are unavoidable because the stronger agent has no incentive to consent to randomization.

Equipped with theoretical predictions, we conduct a laboratory experiment to examine the conditions under which human participants avoid conflict. In the experiment, we alter both

\footnotetext{
${ }^{1}$ When faced with the threat of conflict, individuals seeking a peaceful resolution usually face two problems: (1) a coordination problem, in which agents must assent to mediation, and (2) a commitment problem, in which individuals must agree to bind themselves to the mediated outcome. Here, we limit our attention to problem (1) and assume that there is no commitment issues. For interested readers, the issue of commitment is addressed in studies by Kimbrough and Sheremeta (2012) and Kimbrough et al. (2013).
} 
the availability of a conflict resolution mechanism (random device versus no random device) and the relative strength of agents (weak asymmetry versus strong asymmetry). The results of the experiment indicate that, consistent with the theory, the availability of the random device partially (although not fully) eliminates conflicts when agents are relatively symmetric. Contrary to the theory, however, the device also reduces conflict between substantially asymmetric agents.

We chose to use a random device (a fair coin flip) as a conflict resolution mechanism for a number of reasons. First, using a coin flip is transparent and easy to understand for participants. Second, it provides an ex-ante unbiased allocation of an indivisible resource (consistent with egalitarian norms). Finally, there are many modern and historical examples suggesting that such conflict resolution mechanisms are common in practice.

For example, third-party arbitration can be viewed as a conflict resolution mechanism employing a random device. ${ }^{2}$ Although arbitration can be socially efficient (because it reduces the expenditures the parties must make to compete without arbitration), there is substantial randomness involved in the process (Ashenfelter et al., 1992; Burgess et al., 1996), making arbitration unpredictable (i.e., similar to a coin flip). The nature and degree of this randomness will then influence the likelihood that parties consent to low cost arbitration. Our findings imply that despite these potential social gains, parties may only enter arbitration when their probability of winning in competition is sufficiently close to their probability of winning in arbitration.

Other modern examples of conflict resolution by a random device include rock-paperscissors, drawing straws, and throwing dice. Recently, a judge in Florida required lawyers on

\footnotetext{
2 There is a large experimental literature on arbitration. Deck and Farmer (2007, 2009), Dickinson (2004, 2005), Farmer and Pecorino (2004), and Pecorino and Van Boening (2001, 2004, 2010) experimentally examine various arbitration mechanisms and their impact on the probability and costs of conflict. However, in all these studies the arbitration process is not random and depends (at least implicitly) on the arbitrator's notion of the appropriate split. Moreover, the outcome of arbitration also depends on endogenously chosen offers of conflicting parties. In contrast, the outcome of a random draw does not depend on the preferences of the third party and contestants cannot influence the outcome.
} 
opposing sides of a case to settle a disagreement by rock-paper-scissors. Similarly, the auction houses of Sotheby's and Christie's played the game to determine who would receive a contract to sell $\$ 17.8$ million worth of art. ${ }^{3}$ In some political jurisdictions, a coin flip decides the outcome of elections in which two candidates receive equal numbers of votes, and in other jurisdictions coin flips are employed to determine the recipient of a government contract when two companies tender equal offers (Lissau, 2011). Obviously these cases differ from our setup since the parties are forced into a randomized allocation as a result of a tie. Nevertheless, their use highlights awareness that random devices can reduce the costs of conflict.

Besides modern examples, historically conflict resolution mechanisms using a random device took many forms, including divining rods, the casting of lots, and the inspired interpretation of cracks in fire-heated bones (Bernstein, 1996; Bowden, 2005). All of these mechanisms were used to settle private disputes, determine guilt or innocence, and make decisions related to war and peace, but perhaps the most famous example of conflict resolution via random device is the Delphic Oracle (Bowden, 2005; Iannaccone et al., 2011).

Consider a (hypothetical) dispute between Athens and Sparta over a piece of territory, where the alternative to abiding by the Oracle's proposed allocation is armed conflict. In this context, appealing to the Oracle offers a surplus-preserving solution to a multi-player contest. With evenly matched opponents, the potential cost of conflict may overwhelm the gains to deviation from the Oracle's decision. Hence, the small and autonomous city-states have a strong interest in supporting a randomizing Oracle. However, if Sparta, for example, is sufficiently stronger than Athens, then Sparta may no longer benefit from using a random device. If the gains to conflict are sufficient, then random decisions by the Oracle can only handcuff Sparta's ambition. Indeed, as Greece became a unified empire it no longer had need of the Delphic Oracle

\footnotetext{
${ }^{3}$ See the following news article from the AP: http://www.msnbc.msn.com/id/13221673/ns/us_news-weird_news/
} 
for political purposes. As such by the third century BCE the Oracle was used mainly for religious and personal inquiries (Bowden, 2005), and this is consistent with both our theory and the comparative statics of our experiment.

\section{Background}

A rich literature on conflict resolution in economics extends back to Schelling's (1960) Strategy of Conflict in which he applied the tools of game theory to identify the necessity of credible commitment to avoiding conflict. Since Schelling, economists and others have modeled conflict extensively, emphasizing the resources wasted when conflict occurs (Konrad, 2009). One of the best-known conflict models is the rent-seeking contest, first developed by Tullock (1980) and elaborated by Skaperdas (1996), in which agents expend resources to increase their probabilities of winning a valuable prize. An agent's probability of winning equals his expenditure divided by the sum of all contestants' expenditures, so an agent who expends more resources has a better chance of receiving the prize. In equilibrium, all agents make positive expenditures; however, from the point of view of society, all such expenditures are wasteful. Moreover, laboratory experiments testing this model indicate that in practice the costs of conflict are even higher than predicted by the theory (Dechenaux et al., 2012; Sheremeta, 2013). ${ }^{4}$

Given the high costs of conflict both in theory and practice, a number of mechanisms for eliminating conflict have been proposed, ranging from deterrence via extensive armament (Schelling, 1960; Grossman and Kim, 1995) and hostage exchange (Williamson, 1985) to contractually binding bargaining (Anbarci et al., 2002) and side-payments (Charness et al., 2007; Schoonbeek, 2009; Kimbrough and Sheremeta, 2013). The common property of all such conflict

\footnotetext{
${ }^{4}$ Sheremeta (2013) reviews 30 conflict experiments and finds that in 28 of those experiments individuals exert significantly higher conflict expenditures than predicted. In some cases the expenditures are so high that individuals earn negative expected payoffs (Sheremeta, 2010; Deck and Sheremeta, 2012).
} 
resolution mechanisms is that they seek to alter payoffs in a way that eliminates the incentive for one party to unilaterally initiate conflict. In general, any mechanism that provides all potential combatants with an expected payoff at least as large as their expected payoff from conflict is preferable to outright conflict. Hence, in a dispute over an indivisible resource, random assignment, or assignment by means of an "uncorrelated asymmetry", that is, some asymmetry between players that is uncorrelated with their probabilities of winning a conflict (e.g., property assignment via first possession) can be supported as a Nash equilibrium (e.g., Maynard-Smith, 1982).

Here we explore the decision to employ a random device to avoid costly conflict in a Tullock contest. Prior to the conflict, both parties can choose whether to use the random device. If both parties elect to use the random device, then the contest prize is awarded randomly and no conflict ensues. Otherwise, if one or both of the parties elect not to use the random device, then the two parties engage in a Tullock contest to assign the prize.

One critical assumption underlying both our model and our experiment is that there is no commitment problem. Specifically, we assume that once both parties elect to appeal to the random device, they are bound by its outcome. ${ }^{5}$ In our model the random device addresses the strategic aspect of conflict resolution. Its purpose is to allocate the prize to one party without costly conflict expenditures. Restricting our attention only to the strategic aspects of this conflict resolution mechanism allows us to examine causal effects of power differences on the likelihood of conflict resolution (the crucial role of which is noted by Nietzsche in our opening quote).

\footnotetext{
${ }^{5}$ Bevia and Corchon (2010) examine a model of conflict between two parties when conflict resolution agreements are not binding. Similarly to our findings, they find that even in the absence of binding agreements conflict can be avoided when parties are relatively symmetric. However, conflicts are unavoidable when parties are very asymmetric.
} 


\section{The Conflict Resolution Model}

We model a game of potential conflict between two risk-neutral players for a prize valued at $v$ by both players. The game takes place in two sequential stages, the conflict resolution stage and the conflict stage. In the conflict resolution stage, players 1 and 2 simultaneously decide whether to resolve the conflict by flipping a fair coin or to enter the conflict stage. If both players agree to the random device, then the game ends with neither player advancing to the conflict stage. The prize is allocated to each player with probability $p_{1}{ }^{\text {Random }}=p_{2}{ }^{\text {Random }}=0.5$, and players 1 and 2 receive the expected payoffs of $E\left(\pi_{1}{ }^{\text {Random }}\right)=E\left(\pi_{2}^{\text {Random }}\right)=v / 2$. However, if either player refuses to use the random device, then both players advance to the conflict stage.

In the conflict stage, both players make irreversible effort expenditures $e_{1} \geq 0$ and $e_{2} \geq 0$ to increase their probabilities of receiving the prize. Players have different conflict capabilities (strengths) $a_{1}>0$ and $a_{2}>0$, so that the stronger player $1\left(a_{1}>a_{2}\right)$ can expend the same effort, yet have a higher chance of winning the prize. Specifically, player 1's (similarly player 2's) probability of winning is defined by the following contest success function (Skaperdas, 1996; Clark and Riis, 1998):

$$
p_{1}\left(e_{1}, e_{2}\right)=a_{1} e_{1} /\left(a_{1} e_{1}+a_{2} e_{2}\right) \text { if } e_{1}+e_{2} \neq 0 \text { and } p_{1}\left(e_{1}, e_{2}\right)=1 / 2 \text { if } e_{1}=e_{2}=0 \text {. }
$$

The expected payoff in a conflict for player 1 (similarly player 2 ) is equal to the probability of player 1 winning, $p_{1}\left(e_{1}, e_{2}\right)$, times the prize valuation, $v$, minus contest expenditure, $e_{1}$ :

$$
E\left(\pi_{1}^{\text {Conflict }}\right)=p_{1}\left(e_{1}, e_{2}\right) v-e_{1}=v a_{1} e_{1} /\left(a_{1} e_{1}+a_{2} e_{2}\right)-e_{1} .
$$

By differentiating (2) we receive the First Order Condition (FOC) for player 1 which can be used to obtain a best response function of player 1 given the effort choice $e_{2}$ by player 2 :

$$
v a_{1} a_{2} e_{2} /\left(a_{1} e_{1}+a_{2} e_{2}\right)^{2}-1=0 .
$$

Similarly, the FOC for player 2 is 


$$
v a_{1} a_{2} e_{1} /\left(a_{1} e_{1}+a_{2} e_{2}\right)^{2}-1=0 .
$$

Solving the best response functions (3) and (4) simultaneously, we obtain a unique pure strategy Nash equilibrium which defines effort expenditures for players 1 and $2:^{6}$

$$
e_{1}{ }^{*}=e_{2}{ }^{*}=v a_{1} a_{2} /\left(a_{1}+a_{2}\right)^{2} .
$$

Note that both players expend the same effort in equilibrium. To see the intuition behind this, consider a simple symmetric case of $a_{1}=a_{2}$. In such a case, both players have the same marginal benefit of expending effort, i.e., the same effort by both players implies the same probability of winning. As $a_{1}$ increases, the only thing that changes is the marginal probability of winning, while the marginal costs remain the same. Therefore, when $a_{1}$ increases, player 1 can obtain the same marginal benefit by expending lower effort. The reverse is true for player 2 . This means that player 2 should reduce effort expenditures in order to equate marginal benefit to marginal cost, thus maximizing the expected payoff. This result is well known in the contest literature (Konrad, 2009; Dechenaux et al., 2012).

Given the equilibrium effort expenditures (5), the probabilities of winning the contest by players 1 and 2 are:

$$
p_{1}{ }^{*}=a_{1} /\left(a_{1}+a_{2}\right) \text { and } p_{2}{ }^{*}=a_{2} /\left(a_{1}+a_{2}\right) .
$$

The expected payoffs of players 1 and 2 in the equilibrium are:

$$
E\left(\pi_{1}^{*}\right)=v a_{1}^{2} /\left(a_{1}+a_{2}\right)^{2} \text { and } E\left(\pi_{2}^{*}\right)=v a_{2}^{2} /\left(a_{1}+a_{2}\right)^{2} .
$$

Hence, the contest is both individually costly to the loser and socially costly because all conflict stage expenditures are wasted. As a result, if both players possess complete knowledge of the game's structure and incentives, they may prefer to avoid the conflict stage by flipping the

\footnotetext{
${ }^{6} \mathrm{We}$ focus our attention on pure strategy equilibria only.
} 
coin. ${ }^{7}$ In fact, the weaker player 2 will always choose the random device over the conflict, since his expected payoff in the case of conflict is lower than in the case of a coin flip, i.e., $E\left(\pi_{2}{ }^{\text {Conflict }}\right)$ $=v a_{2}{ }^{2} /\left(a_{1}+a_{2}\right)^{2}<v a_{2}{ }^{2} /\left(a_{2}+a_{2}\right)^{2}=v / 4<v / 2=E\left(\pi_{2}{ }^{\text {Random }}\right)$. However, the choice of player 1 crucially depends on how much stronger player 1 is than player 2 . In particular, player 1 will choose the coin flip only if $E\left(\pi_{1}^{\text {Conflict }}\right)=v a_{1}^{2} /\left(a_{1}+a_{2}\right)^{2} \leq v / 2=E\left(\pi_{1}^{\text {Random }}\right)$, or when $a_{2} \geq(\sqrt{ } 2$ 1) $a_{1}$.

Hence, our theory predicts that if players' capabilities are relatively symmetric, then conflicts will be avoided via a random device. ${ }^{8}$ However, when the asymmetry is substantial then conflicts are unavoidable because the stronger party will always choose to enter the conflict. In what follows we explore the case of a fair coin $\left(p_{1}^{\text {Random }}=p_{2}{ }^{\text {Random }}=0.5\right)$ and there are no costs of using the coin $\left(c_{1}=c_{2}=0\right)$. Note that if we increase the probability that the random device assigns the prize to the stronger player, i.e., $p_{1}{ }^{\text {Random }}>p_{2}{ }^{\text {Random }}$, we can again create a random device that both players would prefer over conflict. Indeed, because a random device is always surplus-preserving, there exists a random device (a coin) that would be preferred by both players for any costly conflict situation. Even if the random device itself is costly (i.e., $c_{1}>0$ and $c_{2}>0$ ), it is preferable by both players as long as individual (expected) costs of using the random device are less than individual (expected) benefits of avoiding conflicts through the random device, i.e., $c_{1} \leq E\left(\pi_{1}^{\text {Random }}\right)-E\left(\pi_{1}^{\text {Conflict }}\right)$ and $c_{2} \leq E\left(\pi_{2}^{\text {Random }}\right)-E\left(\pi_{2}^{\text {Conflict }}\right)$. In the experiment we examine the simplest case of a fair coin (i.e., unbiased random device) and no explicit costs of using a coin flip (nonetheless, participants had to explicitly choose to see the outcome of the random device

\footnotetext{
${ }^{7}$ One can interpret the conflict resolution stage as players bargaining to determine the form of the contest success function, i.e. either completely noisy or lottery contest success function.

${ }^{8}$ In the relatively symmetric case, i.e. $a_{2} \geq(\sqrt{2}-1) a_{1}$, there is also a subgame perfect Nash equilibrium in which both players simultaneously choose not to use the random device. Since the use of random device requires multilateral agreement, if one player chooses not to use the random device then the other player might as well choose not to use it. However, it easy to see that such subgame perfect Nash equilibrium is not strategically stable (Kohlberg and Mertens, 1986), and both players can benefit from unilaterally deviating from it. In fact, we do not find any support for this equilibrium in our data, as weak players almost always choose to use the random device.
} 
each round in the repeated interaction). This allows us to focus on the strategic aspects of the random device as a conflict resolution mechanism and to examine causal effects of power differences (i.e., $a_{1}>a_{2}$ ) on the likelihood of conflict resolution.

\section{Experimental Design and Procedures}

We employ four treatments to test the predictions of our theory: Baseline-Unbalanced, Baseline-Balanced, Random-Unbalanced, and Random-Balanced, where Unbalanced and Balanced refer to the relative strengths of players 1 and 2. The outline of the experimental design and the theoretical predictions for each treatment are shown in Table 1. In all treatments participants compete for a prize with value $v=100$. In the Baseline-Unbalanced treatment, players 1 and 2 have substantially different strengths, i.e., $a_{1}=4$ and $a_{2}=1$. In equilibrium, the expenditures of players 1 and 2 are $e_{1}{ }^{*}=16$ and $e_{2}{ }^{*}=16$, the probabilities of winning are $p_{1}{ }^{*}=$ 0.8 and $p_{2}{ }^{*}=0.2$, and the expected payoffs are $E\left(\pi_{1}{ }^{\text {Conflict }}\right)=64$ and $E\left(\pi_{2}{ }^{\text {Conflict }}\right)=4$. In the Baseline-Balanced treatment, players 1 and 2 have relatively symmetric strengths, i.e., $a_{1}=3 / 2$ and $a_{2}=1$. In equilibrium players 1 and 2 expend $e_{1}{ }^{*}=24$ and $e_{2}{ }^{*}=24$, win the conflict with probabilities $p_{1}{ }^{*}=0.6$ and $p_{2}{ }^{*}=0.4$, and earn expected payoffs of $E\left(\pi_{1}{ }^{\text {Conflict }}\right)=36$ and $E\left(\pi_{2}^{\text {Conflict }}\right)=16$. Thus, the costs of conflict are increasing in the relative symmetry of the players.

The other two treatments, Random-Unbalanced and Random-Balanced introduce the conflict resolution stage to the game, prior to the conflict stage. In the conflict resolution stage, players simultaneously decide whether to flip a coin in order to determine the winner of the prize. In case of disagreement or joint refusal to use the random device, both treatments are equivalent to Baseline-Unbalanced and Baseline-Balanced treatments. The equilibrium 
prediction in the Random-Unbalanced treatment is that conflict always occurs, because the stronger player 1 always chooses to enter the conflict since $E\left(\pi_{1}^{\text {Conflict }}\right)=64>50=E\left(\pi_{1}^{\text {Random }}\right)$. On the other hand, in the Random-Balanced treatment, conflict never occurs, because both players always agree to use the random device since $E\left(\pi_{1}^{\text {Conflict }}\right)=36<50=E\left(\pi_{1}^{\text {Random }}\right)$.

180 participants were recruited at random from the subject pool consisting of graduate and undergraduate students at a private university in the United States. Participants were randomly assigned into 8 experimental sessions (2 per treatment) with between 20 and 24 participants each. Participants sat at, and interacted via, visually isolated computer terminals, and instructions were read aloud by the experimenter as participants followed along on paper. ${ }^{9}$ The experiments were programmed using z-Tree (Fischbacher, 2007). At the beginning of each session participants took a quiz (non-incentivized) to confirm their understanding of the experimental procedures.

Each experimental session consisted of 30 periods of a single treatment. Participants were randomly assigned the initial role of either player 1 or player 2 , and each player 1 was matched with a player 2. Participants remained in this role and matched pair for the first 15 periods of the session. Then all players 1 became players 2 and vice versa, and each participant was randomly re-matched with another participant in the session (who had previously been in the opposite initial role) to form a new pair for the final 15 periods. Each period, in the Baseline-Unbalanced and Baseline-Balanced treatments participants chose their expenditures, any integer between 0 and 100 , which determined their probabilities of winning the prize of 100 francs. At the end of each period, the computer displayed these expenditures, as well as corresponding payoffs. In the Random-Unbalanced and Random-Balanced treatments, participants first made their decisions

\footnotetext{
9 Instructions for the Random-Unbalanced treatment are included in an appendix. Instructions for the other treatments are available upon request.
} 
whether to flip a computerized coin in order to determine who would receive the prize, or to enter the second stage conflict. The computer displayed participants' first stage decisions. Then, if at least one of the paired players decided not to flip the coin, participants proceeded to the second stage where they chose their expenditures. At the end of each period, the computer displayed individual decisions, as well as corresponding payoffs, to each participant.

At the end of the session, we randomly selected 4 of the 30 periods for payment. Participants' total earnings from these 4 periods were added to or subtracted from an initial endowment of 500 francs (which we described as a participation fee). We converted francs to USD at a rate of $25=\$ 1$, and participants were paid privately in cash and dismissed from the experiment. The average experimental earnings, including the \$20 participation fee, were \$24.9, ranging from a low of $\$ 11.6$ to a high of $\$ 35.6$. Sessions lasted approximately an hour each.

Before reporting the results, it is important to comment on some elements of our design. First, we elected to induce strength asymmetries $\left(a_{1} \neq a_{2}\right)$ in all treatments so that differences in behavior can be directly attributed to the degree of strength asymmetry, and not simply to whether players were symmetric or not. Second, our role-switching protocol helps mitigate concerns about expected-payoff inequity across participants. Furthermore, we chose to use fixed matching to reduce the potential for contamination of participants' behavior in one session by outliers (i.e., in a random matching environment the presence of several outliers could substantially impact the behavior of all participants in the session) and to mirror the repeated interactions parties in our historical examples faced. ${ }^{10}$ Finally, we chose to pay participants based on a random subset of periods to increase the per-chosen-period payoff (and thus the salience of

\footnotetext{
${ }^{10}$ Subjects were informed that the session would last for exactly 30 periods, so the stage equilibrium prediction also holds for this finitely repeated game. Nevertheless, it is frequently observed in the experimental literature (i.e., Selten and Stoecker, 1986) that even in finitely-repeated games with a unique equilibrium subjects often choose to cooperate and achieve higher payoffs. This is not a problem for our design since we are interested in treatment effects, and all treatments employ a fixed matching protocol.
} 
the decision), without increasing the cost of running the experiment, and to reduce wealth effects and other confounding path-dependencies that are not part of the economic system being modeled.

\section{Results}

Table 2 reports the aggregate experimental results across the four treatments, including the average expenditure, payoff, probability of entering the conflict and economic surplus. Most of our statistical analysis is based on panel regressions. To control for repeated measures, our regressions (both linear and probabilistic) employ random-effects models. We also control for learning by including a period trend and for role-switching by including a dummy-variable for the last 15 periods after participants switch roles. Finally, treatment effects are captured by dummy-variables.

\subsection{Surplus}

One of the main research questions of our study is whether the availability of the random device reduces the cost of conflict and increases economic surplus. Comparing surpluses in Table 2, we find that surplus is $39 \%$ higher in the Random-Unbalanced than the BaselineUnbalanced treatment (76.1 versus 54.8), and it is 69\% higher in the Random-Balanced than the

Baseline-Balanced treatment (75.8 versus 44.9). Figure 1, displaying time series of mean pairwise surplus for each treatment, indicates that the difference between treatments persists throughout the experiment (although it declines over time). To support these findings statistically, we estimate panel regressions separately for the Unbalanced treatments and for the Balanced treatments where the dependent variable is pairwise surplus, defined as $v-\left(e_{1}+e_{2}\right)$ for 
each pair in each period, and the independent variables are a period trend, a dummy-variable controlling for the last 15 periods after participants switch roles, and a dummy-variable for the presence of the random device. We include a random effects error structure for the individual participants to account for repeated measures, which is equivalent to group random effects since surplus is measured at the level of the pair.

The estimation results are shown in Table 3. Mixed evidence on the significance of the period trend indicates increasing surplus over time in the Unbalanced treatments, though not in the Balanced treatments. ${ }^{11}$ The insignificant estimated effect of switching roles reveals the absence of notable re-matching effects. More important for our purposes, regressions (1) and (2) indicate that the effect of the random device on surplus is positive and significant for both treatments ( $\mathrm{p}$-values $<0.01)$. However, relative to theoretical benchmarks, surplus in the Random-Unbalanced treatment is significantly higher than predicted (76.1 versus 68); while in the Random-Balanced treatment, it is significantly lower than predicted (75.8 versus 100$).{ }^{12} \mathrm{We}$ summarize these findings in Result 1.

Result 1: The random device increases mean surplus in both treatments. However, the surplus is significantly higher than predicted in the Random-Unbalanced treatment and significantly lower in the Random-Balanced treatment.

Does the deviation from the theory derive from the entry decisions in the conflict resolution stage or from expenditures in the conflict stage? The estimations of regressions (3) and (4) in Table 3 provide the first insight. These regressions use only those observations that

\footnotetext{
${ }^{11}$ As can be seen in Figure 3, discussed in Section 5.3, this is largely due to relatively high early-period conflict expenditures in the Unbalanced treatments.

12 Separately for the Random-Unbalanced and Random-Balanced treatments, we estimate random effects panel regressions in which the dependent variable is surplus and the independent variables are a constant, a period trend, and a dummy-variable controlling for switched roles. A Wald test indicates that the estimated constant, which captures surplus given an insignificant coefficient on the period trend, is significantly higher than predicted in the Random-Unbalanced treatment $(\mathrm{p}$-value $=0.02)$ and significantly lower than predicted in the Random-Balanced treatment (p-value $<0.01)$.
} 
resulted in conflict. The estimated effect of the random device is insignificant for both the Unbalanced and Balanced treatments, indicating that higher surplus in the Random-Unbalanced and Random-Balanced treatments mainly comes from decisions not to enter the conflict. When conflict occurs in the Random-Unbalanced and Random-Balanced treatments, it is neither more nor less intense than conflict in the Baseline-Unbalanced and Baseline-Balanced treatments. In the next section we further analyze how entry decisions differ from the theoretical predictions, therefore implicitly shaping Result 1.

\subsection{Probability of a Conflict}

The primary source of deviations between observed and predicted surplus in Result 1 is deviation from the predicted frequency of using the random device to settle conflicts. In particular, Table 2 reports that participants in the Random-Balanced treatment enter conflict with probability 0.40 , although the theory predicts that no conflict will occur. On the other hand, the Random-Unbalanced participants enter conflict with probability 0.63 , though theory predicts that they will fight with probability 1 . Figure 2 displays time series of conflict entry probability by participant type. Although observed probabilities of entry clearly differ from the Nash equilibrium, each player type moves in the direction of the predictions over time. Moreover, when conflict occurs, the stronger player usually instigates, and the probability of entry by strong players is higher in the Random-Unbalanced than the Random-Balanced treatment. Finally, weaker players typically choose not to enter conflict, regardless of their relative strength.

To support these observations, we estimate panel probit models with random effects for each participant, where the dependent variable takes a value of 1 if a player chose to engage in conflict and 0 otherwise. The independent variables are a constant term, a dummy-variable for 
the weaker player 2, a period trend, a weaker-period interaction term to account for separate learning trends by player type, and a dummy-variable controlling for switched roles after period 15. Table 4 reports estimation results. An insignificant estimated coefficient of the role-switching dummy indicates no notable changes as a result of re-matching. However, for the RandomUnbalanced treatment, stronger players significantly increase and weaker players significantly decrease their probabilities of entering conflict over time. In the Random-Balanced treatment, both period trends have signs matching that in the Random-Unbalanced treatment, but the effects are insignificant (period $\mathrm{p}$-value $=0.43$ and period-weaker $\mathrm{p}$-value $=0.14$ )

Furthermore, our results are consistent with the comparative statics predictions of the model. The weaker player 2 chooses to engage in conflict significantly less often than the stronger player 1 . However, as noted above, the overall probability of a conflict is lower than the predicted value of 1 in the Random-Unbalanced treatment and higher than 0 in the RandomBalanced treatment. Table 4 reports an additional estimation combining data from the RandomUnbalanced and Random-Balanced treatments (column 3). Again consistent with the comparative statics predictions, the Unbalanced coefficient is positive, indicating that the probability of a conflict increases in players' asymmetry. We summarize these findings in Result 2.

Result 2: The probability of a conflict is higher when players are more asymmetric, and players' choices are increasingly aligned with the theory over time. There are significantly fewer conflicts than predicted in the Random-Unbalanced treatment and significantly more conflicts in the Random-Balanced treatment.

These findings support our claim that the divergence between the observed and predicted impact of the random device on surplus in both treatments (Result 1) can largely be traced to 
differences between the observed and predicted probabilities of conflict (Result 2). What can explain why we observe "too little" conflict in the Random-Unbalanced and "too much" conflict in the Random-Balanced treatment?

To begin, note that it is unlikely that other-regarding preferences could explain deviations of conflict entry decisions from the point predictions of the theory. On the one hand, if subjects are inequality averse (Fehr and Schmidt, 1999; Bolton and Ockenfels, 2000) then the stronger player 1 should have strong incentives to avoid conflict in both the Random-Unbalanced and Random-Balanced treatments which would lead to "too little" conflict in both treatments. On the other hand, if subjects are spiteful (Leininger, 2003; Herrmann and Orzen, 2008; Mago et al., 2013) then the stronger player 1 should have strong incentives to engage in conflict that would lead to "too much" conflict in both treatments. Similarly, it is unlikely for risk-aversion or lossaversion to explain our results, because both would predict lower levels of conflict in both treatments (Shupp et al., 2013). ${ }^{13}$

Despite the fact that neither other-regarding preferences nor risk preferences can account for deviations of conflict entry decisions from the theory, there are two non-exclusive alternative explanations. First, note that the predicted probabilities of conflict are at the boundaries. The problem of boundary equilibrium predictions has been well recognized in dictator games (List, 2007) and linear public good games (Laury and Holt, 2008), and it has been proposed as an explanation for excessive giving and overcontribution to public goods. Similar argument can be used to explain our Result 2. In the Random-Unbalanced treatment the prediction is that the

\footnotetext{
${ }^{13}$ The distorted probability perceptions of Tversky and Kahnemann (1992) might help explaining why there is "too little" conflict in the Random-Unbalanced treatment. Specifically, if the stronger player 1 underestimates his actual probability of winning the contest (i.e., 0.80 ) and overestimates player 2's actual probability of winning (i.e., 0.2 ) then player 1 may choose to avoid conflict significantly more often than predicted. However, because probabilities are very close to 0.5 in the Random-Balanced treatment (i.e., 0.60 and 0.40 ), there should be almost no probability distortion according to Tversky and Kahnemann (1992), and thus we should not see any deviations from the theory. Therefore, it appears that the distorted probability perceptions can explain only part of our data.
} 
probability of conflict should be one while in the Random-Balanced treatment it should be zero. Therefore, if subjects make mistakes it would imply a conflict rate less than one in the RandomUnbalanced treatment and more than zero in the Random-Balanced treatment, which is consistent with our findings.

Second, the deviation from theory can also be explained by the relatively weak incentives faced by the stronger player. Note that when comparing individual probability of choosing conflict (see Table 2), the weaker player 2 hews to the predictions of the theory rather well while the stronger player 1 does not. Theoretically, in the Random-Unbalanced treatment, by engaging in a conflict instead of using a coin flip, player 1 gains 14 in expectation $(64-50=14)$ while player 2 loses $46(4-50=-46)$. In the Random-Balanced treatment, by engaging in a conflict, player 1 loses $14(36-50=-14)$ while player 2 loses $34(16-50=-36)$. Thus, by conforming to the theory player 1 gains in both treatment about $28 \%(14 / 50=0.28)$, which may be a relatively low incentive causing "too little" conflict in the Random-Unbalanced and "too much" conflict in the Random-Balanced treatment.

Whether the relatively weak incentives faced by the stronger player or the end point predictions produce deviations of individual entry decisions from point predictions, the comparative statics of the conflict resolution model hold in our experiment, suggesting that a random device can serve as an effective conflict resolution mechanism. This is encouraging, given that many earlier experiments have documented very high costs of conflict (Davis and Reilly, 1998; Potters et al., 1998; Fonseca, 2009; Sheremeta, 2010, 2011; Cason et al., 2012, 2013; Morgan et al., 2012). Indeed, the same pattern emerges in our experiment. As we show in the next section, when conflict occurs, the costs exceed the predictions of the theory. 


\subsection{Conflict Expenditures}

Table 2 reports mean expenditures in excess of the Nash equilibrium predictions for both player types in all treatments, and Figure 3, which displays time series of mean individual expenditure by role and treatment, also shows that the excess expenditures persist throughout the experiment, though there is some early decline, particularly in the Baseline-Unbalanced treatment.

To examine the determinants of expenditures, we combine the data across treatments and estimate a single panel regression in which the dependent variable is expenditure and the independent variables are a dummy-variable for the weaker player 2, a period trend, a dummyvariable for the last 15 periods indicating the periods after roles have switched, Unbalanced and Random treatment dummies, and a constant term. For the Random-Balanced and RandomUnbalanced treatments we restrict analysis to instances of conflict. As before, we include a random effects error structure for the individual participants to account for repeated measures.

Table 5 displays the output of this regression. As in the other regressions, the estimated coefficient of the role-switching dummy is insignificant. Furthermore, the period trend, the period-weaker interaction, and the weaker dummy variable are all insignificant. However, when allowing for separate trends for each player type by treatment, there was a negative and significant trend for both types in the Baseline-Unbalanced treatment ( $\mathrm{p}$-values $<.05$; also see Figure 3). Most importantly, consistent with the theory, expenditures decrease as players become more asymmetric (the coefficient on Unbalanced is negative and significant).

One might expect that the forgone opportunity to avoid the costs of conflict would induce retaliatory behavior by those participants that chose not to enter but were dragged into conflict by their counterpart. The insignificant effect of the random device on conflict expenditures, 
conditional on entry, indicates that conflict intensity remains unchanged in the presence of the random device. ${ }^{14}$ Nevertheless, Wald tests reject the hypotheses that the constant term is equal to 24 (the predicted expenditure in the Balanced treatments) and that the sum of the constant and the Unbalanced dummy-variable is equal to 16 (the predicted expenditure in the Unbalanced treatments) (p-values < 0.01). We summarize these findings in Result 3.

Result 3: Although participants overinvest in conflict on average, expenditures of both types are lower when players are more asymmetric. Furthermore, for a given asymmetry level, there is no difference in expenditures between stronger and weaker players.

The fact that subjects overinvest in our experiment is not surprising. Sheremeta (2013) finds that in 28 out of 30 experimental studies (employing lottery contests) subjects overinvest in conflict relatively to the Nash equilibrium prediction. There are a number of explanations which can explain this phenomena. First, there is evidence that in addition to monetary incentives, subjects derive a non-monetary utility from winning (Sheremeta, 2010; Cason et al., 2012; Price and Sheremeta, 2013). Second, several studies show that overinvestment may be driven by spiteful preferences (Cason et al., 2013; Eisenkopf and Teyssier, 2013; Mago et al., 2013). Third, it is likely that subjects make mistakes which add noise to the Nash equilibrium solution, and thus may cause overinvestment in contests (Sheremeta, 2011; Chowdhury et al., 2013; Lim et al., 2013). Finally, the way the incentives are structured in the contest can also have a significant bearing on the amount of overinvestment (Chowdhury et al., 2013). All of the aforementioned factors can help explaining our findings; however, there is no consensus in the literature as to which factors are the most important (Dechenaux et al., 2012; Sheremeta, 2013).

\footnotetext{
${ }^{14}$ As a robustness check in the Random-Balanced and Random-Unbalanced treatments, we have also estimated the regression in Table 5 controlling for the individual entry decisions in the conflict resolution stage. Estimation results are virtually the same and are available from authors upon request.
} 
While our experiment was not designed to test this hypothesis in particular, the data suggest that, ceteris paribus, conflict expenditures decline with relative strength asymmetry in repeated Tullock contests, and this finding is consistent with a wider literature. For example, in animal behavior studies, one common explanation for conflict behavior is based on "fighting assessment" (Parker, 1974). So-called "mutual assessment" models hold that in resource contests, animals assess the relative strength of their opponents, and upon recognizing an unfavorable asymmetry they are less likely to expend resources in conflict, thereby reducing the total costs of conflict. ${ }^{15}$ Empirical evidence from a broad range of species shows that the average length of resource contests is decreasing in the relative asymmetry of the competitors (Arnott and Elwood, 2009). Finally, several recent experimental studies have also documented that increasing players' asymmetry reduces effort expenditures in diverse competitive environments (Fonseca, 2009; Anderson and Freeborn, 2010; DeScioli and Wilson, 2011).

\section{Conclusion}

Our model of conflict resolution between asymmetric contestants predicts that when players are sufficiently symmetric, they will choose to settle their disputes by using a random device in order to avoid a costly conflict. On the other hand, if players are sufficiently asymmetric, the stronger player will always choose outright conflict because the expected benefits of conflict exceed the expected value of the random allocation. We test these theoretical predictions in the laboratory with two treatments, one in which the players are relatively Balanced and one in which they are Unbalanced. In keeping with previous studies of conflict we find evidence that conflicts are generally more costly than expected, as conflict expenditures are higher than predicted in all treatments. Also, consistent with previous animal behavior and

\footnotetext{
${ }^{15}$ As the Kenny Rogers lyric famously reads, "You gotta know when to hold 'em, know when to fold 'em..."
} 
human participant research on the intensity of conflict with respect to the relative strength asymmetry of the contestants, we find that expenditures are greater in the Balanced treatments than in the Unbalanced treatments. Most importantly, we find compelling evidence that the random device reduces the costs of conflict in both treatments: when agents are relatively symmetric, the random device increases average surplus by $69 \%$, and when they are relatively asymmetric, it still increases average surplus by $39 \%$.

Our results highlight the power of randomized allocation as a surplus-preserving conflict resolution mechanism and explain both historical and modern implementations of such mechanisms ranging from the Delphic Oracle in archaic Greece to third-party arbitration. Although there is substantial randomness involved in the process of arbitration, we find that as long as the probability of winning a conflict is close to the probability of winning in arbitration, there is a high chance that the conflict will be avoided. Similarly, many superficially mystifying practices that appear absurd to modern eyes can be revealed to serve as conflict resolution mechanisms. It is also important to emphasize that the random device is most successful in resolving conflicts between relatively symmetric agents, which according to prior research tend to engage in more costly conflicts than more asymmetric agents (Davis and Reilly, 1998; Fonseca, 2009; Anderson and Freeborn, 2010; DeScioli and Wilson, 2011).

Both the data and the theory suggest a number of interesting extensions. Although it is clear why the random device may work as a surplus-preserving conflict resolution mechanism, it is not obvious why agents would commit to a proposed resolution after observing an ex post unfavorable decision by the random device. In this paper we ensure that agents abide by the outcome of the random device by enforcing binding contracts. However, in practice, agents cannot always enter binding contracts. As in our introductory example, it is unclear what would 
prevent Athens from rejecting the Oracle's counsel and fighting Sparta anyway if Sparta was favored by the decision. ${ }^{16}$ Future research should examine commitment problems in conflict resolution.

Another interesting question is how much participants would be willing to pay in order to use a random device; the theoretical willingness to pay is noted in Section 3, but if there exists a threshold for provision of the random device as a public good, then the collective action problem may reduce the likelihood of surplus preserving solutions. On the other hand, one could ask whether various side-payment schemes would increase the willingness of strong players to consent to randomization, and if participants can bargain over the assigned probabilities, the observed surplus gains may be extended to even more asymmetric environments.

Finally, it would be interesting to examine how the change of a payoff structure as well as use of an unfair coin flip impacts conflict resolution rates. For example, one could design an experiment with an unfair coin such that both players would like to avoid conflict in the asymmetric case, but the weaker player would choose to enter conflict in the symmetric case. This would be a very interesting extension that we leave for future research.

\footnotetext{
${ }^{16}$ Two reasons why agents committed to the Oracle's decisions in ancient times were historical context and the perceived 'mystical' nature of such decisions (Iannaccone et al., 2011), and reputational concerns resulting from repeated interaction with one another and with the Oracle (Dellarocas, 2006).
} 


\section{References}

Anbarci, Nejat, Stergios Skaperdas, and Constantinos Syropoulos. 2002. "Comparing bargaining solutions in the shadow of conflict: how norms against threats can have real effects." Journal of Economic Theory, 106(1), 1-16.

Anderson, Lisa, and Beth Freeborn. 2010. "Varying the intensity of competition in a multiple prize rent seeking experiment." Public Choice, 143(1), 237-254.

Arnott, Gareth, and Robert W. Elwood. 2009. "Assessment of Fighting Ability in Animal Contests." Animal Behavior, 77, 991-1004.

Ashenfelter, Orley, Janet Currie, Henry S. Farber and Matthew Spiegelet. 1992. "An Experimental Comparison of Dispute Rates in Alternative Arbitration Systems." Econometrica, 60(6), 1407-33.

Bernstein, Peter. 1996. Against the Gods: The Remarkable Story of Risk. New York: John Wiley \& Sons.

Beviá, Carmen, and Luis C. Corchón. 2010. "Peace agreements without commitment." Games and Economic Behavior, 68(2), 469-487.

Bowden, Hugh. 2005. Classical Athens and the Delphic oracle: divination and democracy. Cambridge; New York: Cambridge University Press.

Burgess, Paul L., Marburger, Daniel R., and Scoggins, John F. 1996. "Do Baseball Arbitrators Simply Flip a Coin?" In Baseball Economics, J. Fizel et al eds., Praeger: Westport, CT.

Cason, Timothy N., Roman M. Sheremeta, and Jingjing Zhang. 2012. "Communication and efficiency in competitive coordination games." Games and Economic Behavior, 76(1), 26-43.

Cason, Timothy N., William Masters, and Roman M. Sheremeta. 2013. "Winner-take-all and proportional-prize contests: theory and experimental results." Chapman University, Working Paper.

Charness, Gary, Guillame R. Frechette, and Cheng-Zong Qin. 2007. "Endogenous Transfers in the Prisoner's Dilemma Game: An Experimental Test of Cooperation and Coordination." Games and Economic Behavior, 60(2), 287-306.

Chowdhury, Subhasish M., Roman M. Sheremeta, and Theodore L. Turocy. 2013. "Overbidding and overspreading in rent-seeking experiments: cost structure and prize allocation rules." Chapman University, Working Paper.

Clark, Derek J., and Christian Riis. 1998. "Contest success functions: an extension." Economic Theory, 11(1), 201-204.

Davis, Douglas, and Robert Reilly. 1998. "Do Many Cooks Always Spoil the Stew? An Experimental Analysis of Rent Seeking and the Role of a Strategic Buyer." Public Choice, 95, 89-115.

Dechenaux, Emmanuel, Dan Kovenock, and Roman M. Sheremeta. 2012. "A Survey of Experimental Research on Contests, All-Pay Auctions and Tournaments." Chapman University, Working Papers.

Deck, Cary A. and Amy Farmer. 2007. "Bargaining Over an Uncertain Value: Arbitration Mechanisms Compared." Journal of Law, Economics and Organization, 23(3), 547-579.

Deck, Cary A. and Amy Farmer. 2009. "Strategic Bidding and Investments in Final Offer Arbitration: Theory and Experimental Evidence." Journal of Economic Behavior and Organization, 70(1-2), 361-73.

Deck, Cary A. and Roman M. Sheremeta. 2012. "Fight or Flight? Defending Against Sequential Attacks in the Game of Siege." Journal of Conflict Resolution, 56, 1069-1088. 
Dellarocas, Chris. (2006). "Reputation Mechanisms.” Handbooks in Information Systems, Vol. I, Handbook on Economics and Information Systems, edited by Terrence J. Hendershott, Elsevier, 629-660.

DeScioli, Peter, and Bart J. Wilson. 2011. "The Territorial Foundations of Human Property." Evolution and Human Behavior, 32(5), 297-304.

Dickinson, David L. 2004. "A Comparison of Conventional, Final-offer, and "Combined' Arbitration for Dispute Resolution.” Industrial and Labor Relations Review, 57(2), 288-301.

Dickinson, David L. 2005. "Bargaining Outcomes with Double-offer Arbitration." Experimental Economics, 8(2), 145-166.

Eisenkopf, Gerald, and Sabrina Teyssier. 2013. "Envy and loss aversion in tournaments." Journal of Economic Psychology, 34, 240-255.

Ernst, Fehr, and Klaus M. Schmidt. 1999. "A Theory Of Fairness, Competition, And Cooperation." Quarterly Journal of Economics, 114(3), 817-868.

Farmer, Amy and Paul Pecorino. 1999. "Legal Expenditure as a Rent-Seeking Game.” Public Choice, 100, 271-288.

Fischbacher, Urs. 2007. "z-Tree: Zurich Toolbox for Ready-Made Economic Experiments." Experimental Economics, 10, 171-178.

Fonseca, Miguel A. 2009. "An experimental investigation of asymmetric contests." International Journal of Industrial Organization, 27(5), 582-591.

Grossman, Herschel I., and Minseong Kim. 1995. "Swords or plowshares? A theory of the security of claims to property." Journal of Political Economy, 1275-1288.

Herrmann, Benedikt, and Henrik Orzen. 2008. "The appearance of homo rivalis: Social preferences and the nature of rent seeking," Working Paper, University of Nottingham.

Iannaccone, Laurence R., Colleen E. Haight, Jared Rubin, 2011. "Lessons from Delphi: Religious markets and spiritual capitals." Journal of Economic Behavior and Organization, 77(3), 326-338.

Kimbrough, Erik O., and Roman M. Sheremeta. 2012. "Why Can't We Be Friends? Entitlements and the Costs of Conflict." Chapman University, Working Paper.

Kimbrough, Erik O., and Roman M. Sheremeta. 2013. "Side-Payments and the Costs of Conflict." International Journal of Industrial Organization, 31(3): 278-286.

Kimbrough, Erik O., Jared C. Rubin, Roman M. Sheremeta, and Timothy Shields. 2013. "Commitment Problems in Conflict Resolution." Chapman University, Working Paper.

Kohlberg, Elon, and Mertens, Jean-Francois 1986. "On the Strategic Stability of Equilibria." Econometrica, 54, 1003-1037.

Konrad, Kai. A. 2009. Strategy and Dynamics in Contests. New York, NY: Oxford University Press.

Laury, Susan K., and Charles A. Holt. 2008. "Voluntary provision of public goods: Experimental results with interior Nash Equilibria." In C. R. Plott \& V. L. Smith (Eds.), Handbook of Experimental Economics Results. (Vol. 1) 792-801. New York: Elsevier.

Leininger, Wolfgang. 2003. "On evolutionarily stable behavior in contests." Economics of Governance, 4(3), 177-186.

Lim, Wooyoung, Alexander Matros, and T. Turocy. 2012 "Bounded rationality and group size in Tullock contests: Experimental evidence." Working paper.

Lissau, Russell. 2011. Coin flips choose winners in Island Lake, Green Oaks. Daily Herald. http://www.dailyherald.com 
List, John A. 2007. "On the interpretation of giving in dictator games." Journal of Political Economy, 115(3), 482-493.

Mago, Shakun Datta, Anya C. Savikhin, and Roman M. Sheremeta. 2013. "Facing Your Opponents: Social Identification and Information Feedback in Contests." Chapman University, Working Paper.

Maynard-Smith, John. 1982. Evolution and the Theory of Games. Cambridge, UK: Cambridge University Press.

Morgan, John, Henrik Orzen, and Martin Sefton. 2012. "Endogenous Entry in Contests." Economic Theory, 51, 435-463.

Nietzsche, Friedrich. 1986. Human, All Too Human, transl. R.J. Hollingdale, Cambridge, UK: Cambridge University Press. (1880)

Parker, G.A. 1974. "Assessment Strategy and the Evolution of Fighting Behavior." Journal of Theoretical Biology, 47, 223-243.

Pecorino, Paul and Mark Van Boening. 2004. "An Empirical Analysis of Bargaining with Voluntary Transmission of Private Information." Journal of Legal Studies, 33(1), 131-156.

Pecorino, Paul and Mark Van Boening. 2010. "Fairness in an Embedded Ultimatum Game." Journal of Law and Economics, 53(2), 263-287.

Potters, Jan C. Casper G. De Vries, and Frans Van Linden. 1998. "An Experimental Examination of Rational Rent Seeking." European Journal of Political Economy, 14, 783-800.

Price, Curtis. \& Roman M. Sheremeta. 2013. "Endowment origin, demographic effects and individual preferences in contests." Journal of Economics and Management Strategy, forthcoming.

Schelling, Thomas. 1960. The Strategy of Conflict. Cambridge, MA: Harvard University Press.

Schoonbeek, Lambeert. 2009. "Bribing Potential Entrants in a Rent-Seeking Contest." Public Choice, 139(1-2), 153-158.

Selten, R., \& Stoecker, R. 1986. "End behavior in sequences of finite Prisoner's Dilemma supergames A learning theory approach." Journal of Economic Behavior and Organization, 7, 47-70.

Sheremeta, Roman M. 2010. "Experimental Comparison of Multi-Stage and One-Stage Contests." Games and Economic Behavior, 68(2), 731-747.

Sheremeta, Roman M. 2011. "Contest design: an experimental investigation." Economic Inquiry, 49(2), 573-590.

Sheremeta, Roman M. 2013. "Overbidding and Heterogeneous Behavior in Contest Experiments." Journal of Economic Surveys, 27, 491-514.

Shupp, Robert, Roman M. Sheremeta, David Schmidt, and James Walker. 2013. "Resource allocation contests: Experimental evidence." Journal of Economic Psychology, 39, 257-267.

Skaperdas, Stergios. 1996. "Contest Success Functions." Economic Theory, 7(2), 283-290.

Tullock, Gordon. 1980. "Efficient Rent Seeking." In Toward a Theory of the Rent-seeking Society, ed. James M. Buchanan, Robert D. Tollison, and Gordon Tullock. 97-112. College Station, TX: Texas A\&M University Press.

Tversky, Amos, and Daniel Kahneman. 1992. "Advances in prospect theory: Cumulative representation of uncertainty." Journal of Risk and uncertainty, 5(4), 297-323.

Williamson, Oliver. 1985. "Credible Commitments: Using Hostages to Support Exchange." American Economic Review, 73(4), 519-540. 


\section{Tables and Figures}

Table 1: Experimental Design and Theoretical Predictions

\begin{tabular}{lccccc}
\hline \hline & \multicolumn{5}{c}{ Treatment } \\
\hline & Player & $\begin{array}{c}\text { Baseline- } \\
\text { Unbalanced }\end{array}$ & $\begin{array}{c}\text { Baseline- } \\
\text { Balanced }\end{array}$ & $\begin{array}{c}\text { Random- } \\
\text { Unbalanced }\end{array}$ & $\begin{array}{c}\text { Random- } \\
\text { Balanced }\end{array}$ \\
\hline Strength, $a$ & 1 & 4 & $3 / 2$ & 4 & $3 / 2$ \\
Expenditure, $e^{*}$ & 2 & 1 & 1 & 1 & 1 \\
\cline { 2 - 6 } & 1 & 16 & 24 & 16 & 24 \\
Probability, $p^{*}$ & 2 & 16 & 24 & 16 & 24 \\
\cline { 2 - 6 } & 1 & 0.80 & 0.60 & 0.80 & 0.60 \\
Expected Payoff, $E\left(\pi^{*}\right)$ & 2 & 0.20 & 0.40 & 0.20 & 0.40 \\
\cline { 2 - 6 } & 1 & 64 & 36 & 64 & 36 \\
Individual Probability of & 2 & 4 & 16 & 4 & 16 \\
Choosing Conflict & 1 & N/A & N/A & 1.00 & 0.00 \\
Probability of a Conflict & 2 & N/A & N/A & 0.00 & 0.00 \\
\cline { 2 - 6 } Surplus & \multicolumn{7}{c}{1.00} & 1.00 & 1.00 & 0.00 \\
\hline
\end{tabular}

Table 2: Aggregate Experimental Results

\begin{tabular}{lccccc}
\hline \hline & \multicolumn{5}{c}{ Treatment } \\
\hline & Player & $\begin{array}{c}\text { Baseline- } \\
\text { Unbalanced }\end{array}$ & $\begin{array}{c}\text { Baseline- } \\
\text { Balanced }\end{array}$ & $\begin{array}{c}\text { Random- } \\
\text { Unbalanced }\end{array}$ & $\begin{array}{c}\text { Random- } \\
\text { Balanced }\end{array}$ \\
\hline Expenditure, $e$ & 1 & $21.4(0.8)$ & $27.9(0.8)$ & $17.8(0.7)$ & $31.8(1.7)$ \\
Probability, $p$ & 2 & $23.7(1.1)$ & $27.2(0.9)$ & $19.7(1.2)$ & $28.4(1.8)$ \\
\cline { 2 - 6 } & 1 & $0.77(0.02)$ & $0.61(0.02)$ & $0.80(0.02)$ & $0.64(0.03)$ \\
Expected Payoff, $E(\pi)$ & 2 & $0.23(0.02)$ & $0.39(0.02)$ & $0.20(0.02)$ & $0.36(0.03)$ \\
\cline { 2 - 6 } & 1 & $55.2(1.7)$ & $33.1(1.8)$ & $61.7(2.1)$ & $32.4(3.1)$ \\
Individual Probability of & 1 & $-0.4(1.6)$ & $11.8(1.8)$ & $0.8(1.8)$ & $7.4(2.9)$ \\
Choosing Conflict & 2 & N/A & N/A & $0.60(0.02)$ & $0.33(0.02)$ \\
Probability of a Conflict & \multicolumn{7}{c}{ N/A } & N/A & $0.06(0.01)$ & $0.13(0.01)$ \\
\cline { 2 - 6 } Surplus & \multicolumn{7}{c}{ 54.0 (1.5) } & 44.9 (1.4) & $76.1(1.2)$ & $75.8(1.6)$ \\
\hline Mean (standard errors) reported. The "Individual Probability of Choosing Conflict" and "Probability \\
\cline { 2 - 6 } of a Conflict" are the empirical probabilities of conflict.
\end{tabular}


Table 3: The Impact of the Random Device on Group Surplus

\begin{tabular}{lcccc}
\hline \hline Regression & $(1)$ & $(2)$ & $(3)$ & $(4)$ \\
\hline Dependent Variable & \multicolumn{4}{c}{ Surplus } \\
\cline { 2 - 5 } & Unbalanced & Balanced & Unbalanced & Balanced \\
\hline Period & $0.502^{* *}$ & -0.082 & $0.713^{* * *}$ & -0.243 \\
[period trend] & $(0.163)$ & $(0.175)$ & $(0.179)$ & $(0.182)$ \\
Switch & -3.722 & 5.549 & -3.954 & 4.918 \\
{$[1$ if period $>15]$} & $(5.935)$ & $(6.543)$ & $(6.071)$ & $(8.476)$ \\
Random & $21.31^{* * *}$ & $30.96^{* * *}$ & 6.150 & -10.41 \\
{$[1$ if Random] } & $(5.478)$ & $(5.939)$ & $(5.461)$ & $(8.495)$ \\
Constant & $48.91^{* * *}$ & $43.36^{* * *}$ & $45.76^{* * *}$ & $46.18^{* * *}$ \\
& $(5.231)$ & $(4.815)$ & $(5.467)$ & $(6.739)$ \\
\hline Observations & 1320 & 1380 & 1090 & 967 \\
Number of groups & 88 & 92 & 86 & 80 \\
\hline
\end{tabular}

*** $\mathrm{p}<0.001, * * \mathrm{p}<0.01, * \mathrm{p}<0.05$. Robust standard errors in parentheses.

Panel linear models (1)-(4) include individual participant random effects.

Regressions (3) and (4) use only those observations which resulted in conflict.

Table 4: Individual Probability of Choosing Conflict

\begin{tabular}{lccc}
\hline \hline Regression & $(1)$ & $(2)$ & $(3)$ \\
\hline Dependent Variable & \multicolumn{3}{c}{ Probability of a Conflict } \\
\cline { 2 - 4 } & \multicolumn{2}{c}{ Random- } & Random- \\
& $-1.345^{* * *}$ & $-0.57^{\wedge}$ & $-0.993^{* * *}$ \\
& $(0.288)$ & $(0.315)$ & $(0.216)$ \\
Weaker & $0.025^{*}$ & -0.011 & $0.017^{*}$ \\
$\quad[1$ if player 2] & $(0.012)$ & $(0.013)$ & $(0.0088)$ \\
Period & $-0.043^{*}$ & -0.029 & $-0.035^{*}$ \\
$\quad[$ period trend] & $(0.018)$ & $(0.019)$ & $(0.014)$ \\
Weaker $\times$ Period & 0.0003 & -0.312 & -0.168 \\
$\quad[$ weaker times period] & $(0.192)$ & $(0.190)$ & $(0.134)$ \\
Switch & & & $0.595^{* *}$ \\
$\quad[1$ if period $>15]$ & & & $(0.207)$ \\
Unbalanced & 0.0997 & $-0.734^{* *}$ & $-0.682^{* * *}$ \\
$\quad[1$ if Unbalanced] & $(0.180)$ & $(0.246)$ & $(0.184)$ \\
Constant & 1260 & 1380 & 2640 \\
& 42 & 46 & 88 \\
\hline Observations & 42 & \\
Number of groups & &
\end{tabular}

$* * * \mathrm{p}<0.001, * * \mathrm{p}<0.01, * \mathrm{p}<0.05,^{\wedge} \mathrm{p}<0.1$. Standard errors in parentheses. Panel probit models (1)-(3) include individual participant random effects. 


\section{Table 5: Determinants of Expenditure}

\begin{tabular}{lc}
\hline \hline Regression & $(1)$ \\
\hline Dependent Variable & Expenditure \\
\cline { 2 - 2 } & All Treatments \\
\hline Weaker & 0.422 \\
{$[1$ if player 2] } & $(2.602)$ \\
Period & -0.158 \\
[period trend] & $(0.09)$ \\
Weaker $\times$ Period & 0.011 \\
[weaker times period] & $(0.152)$ \\
Switch & -0.682 \\
{$[1$ if period $>15]$} & $(1.879)$ \\
Unbalanced & $-7.752^{* *}$ \\
{$[1$ if Unbalanced] } & $(2.486)$ \\
Random & -0.568 \\
[1 if Random] & $(2.503)$ \\
Constant & $31.439 * * *$ \\
& $(2.566)$ \\
\hline Observations & 4114 \\
Number of groups & 177 \\
\hline
\end{tabular}

*** $\mathrm{p}<0.001, * * \mathrm{p}<0.01, * \mathrm{p}<0.05$. Robust standard errors in parentheses. Panel linear model (1) includes individual participant random effects. 


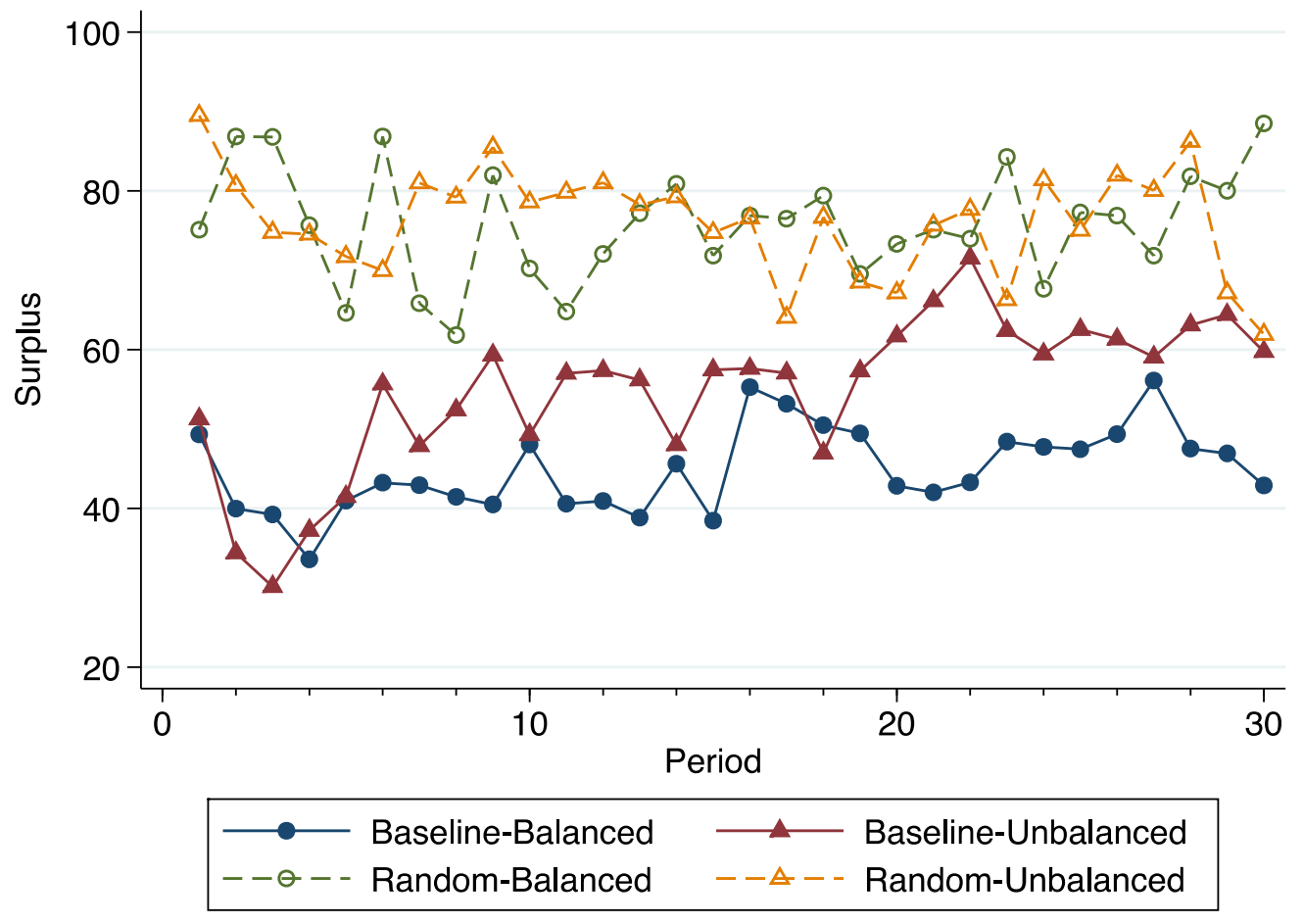

Figure 1: Time Series of Mean Surplus, by Treatment

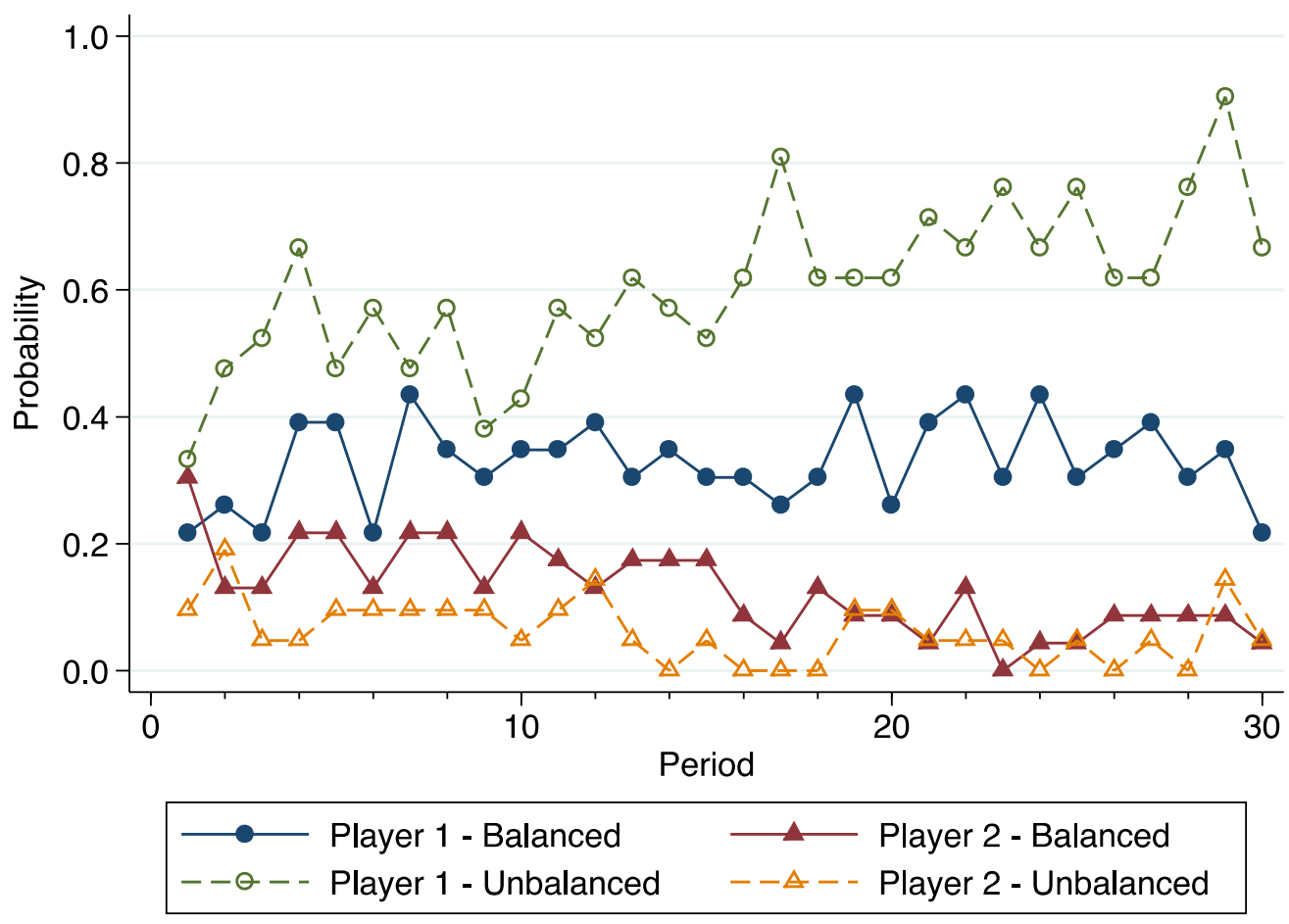

Figure 2: Time Series of Mean Probability of Choosing Conflict by Role, Random Treatments 


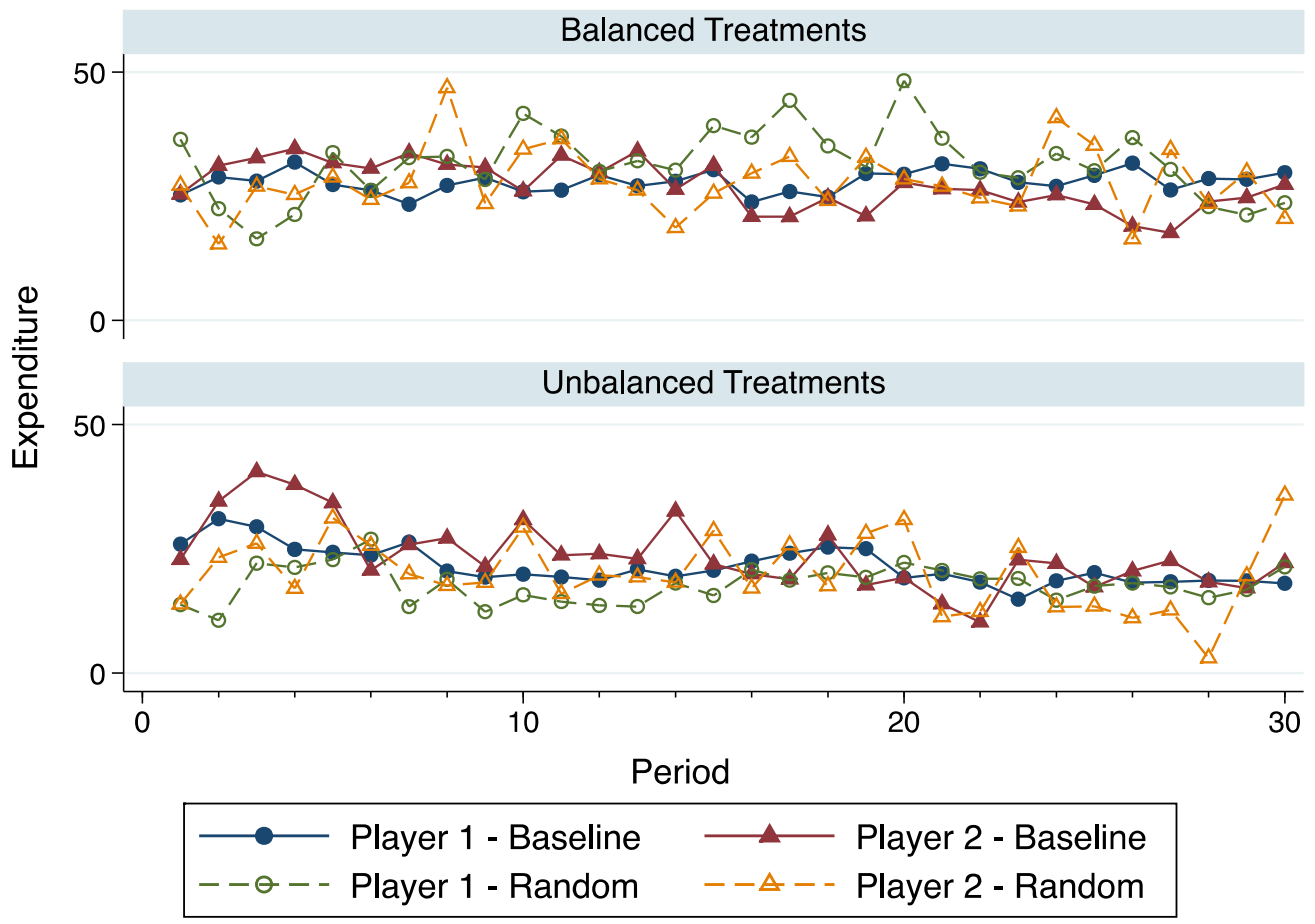

Figure 3: Time Series of Mean Expenditure by Role and Treatment 


\section{Appendix (An Online Supplement) - Instructions for the Random-Unbalanced Treatment}

\section{GENERAL INSTRUCTIONS}

This is an experiment in the economics of strategic decision-making. Various research agencies have provided funds for this research. If you follow the instructions closely and make appropriate decisions, you and the other participants in this experiment can earn an appreciable amount of money, which will be paid to you in cash.

The currency used in the experiment is francs. Francs will be converted to U.S. Dollars at a rate of $\_\mathbf{2 5}$ francs to $\underline{1}$ dollar. You have already earned a $\mathbf{\$ 2 0 . 0 0}$ participation fee (this includes the $\$ 7$ show up fee). The experiment will consist of $\mathbf{3 0}$ periods and at the end of the experiment we will randomly choose $\mathbf{4}$ of the $\mathbf{3 0}$ periods for actual payment. We will sum your total earnings for these 4 periods and convert them to a U.S. dollar payment.

It is very important that you remain silent and do not look at others' decisions (screens). If you have any questions, or need assistance of any kind, please raise your hand and an experimenter will come to you. If you talk, laugh, exclaim out loud, etc..., you will be asked to leave and you will not be paid. We expect and appreciate you following the laboratory's rules. The remainder of the instructions will describe the decisions you may face in each period.

The participants in today's experiment will be randomly assigned into two-person groups. In addition to the group assignment each participant will also be randomly assigned to a specific type in the group, designated as Person 1 or Person 2. You and the other participant in your group will make choices that will determine your payoffs. The experiment contains 30 rounds. You will remain within the same two-person group as the same type for 15 rounds. Thereafter you will be regrouped with another participant into a new group where you will be a different type (i.e., if you were Person 1 in the first 15 rounds, you will be Person 2 for the last 15 rounds, and vice-versa).

In each round of the experiment either Person 1 or Person 2 will receive the reward. The reward is worth $\mathbf{1 0 0}$ francs. Each round of the experiment consists of two decision stages. In Stage 1, you and the other person in your group will decide on a specific way to determine who will receive the reward.

\section{YOUR DECISION IN STAGE 1}

In each round, both participants will have the opportunity to choose whether they want to flip a computer coin in order to determine who will receive the reward. An example of your decision screen is shown below.

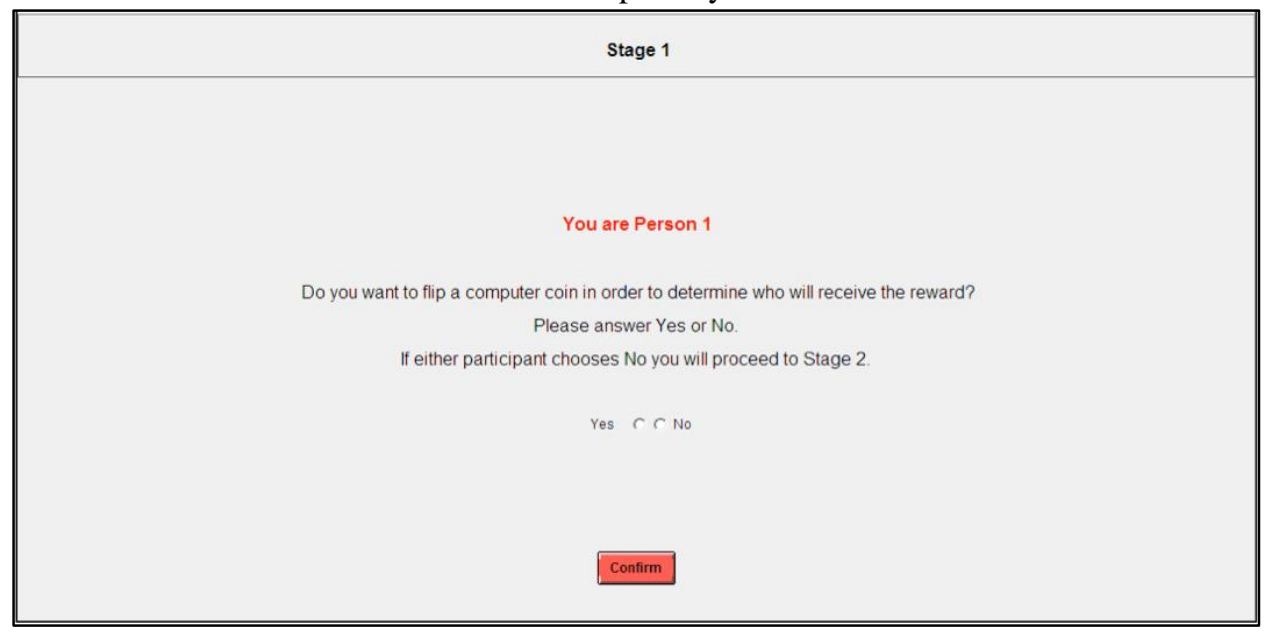

\section{EARNINGS}

If both participants choose to flip a computer coin, the round is over. The flip outcome determines who receives the reward. There is a 50\% chance the coin lands heads, and 50\% chance the coin lands tails. If the computer coin lands heads Person 1 receives the reward, if it lands tails, Person 2 receives the reward. So, there are two possible payoffs:

- If You Receive the Reward

- If The Other Person Receives the Reward
Earnings $=100$ francs

Earnings $=0$ francs 
If you want to flip the coin, check 'Yes'. However, if either Person 1 or Person 2 chooses to not flip, by checking 'No', then both participants will enter Stage 2. At the end of the experiment we will randomly select four out of 30 periods for payment--two from the first 15 periods and two from the last 15 periods.

\section{YOUR DECISION IN STAGE 2}

If either person chooses to enter stage 2 by checking 'No', each person may bid for the 100 franc reward. You may bid any integer number of francs between $\mathbf{0}$ and 100. An example of your decision screen is shown below.

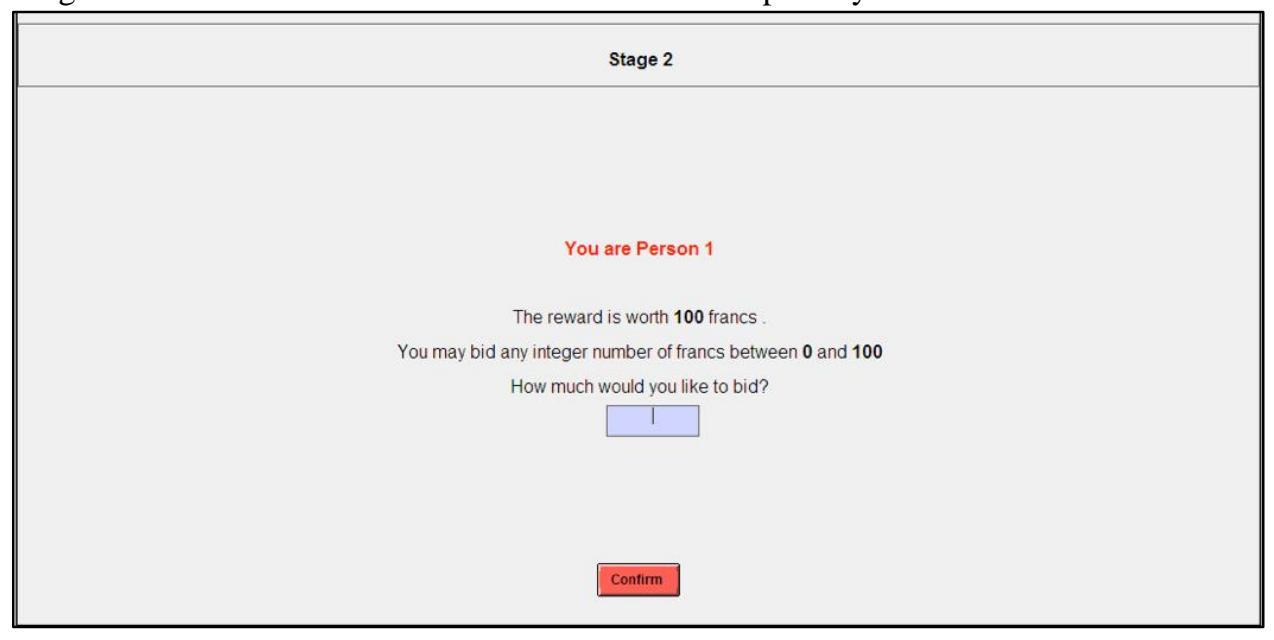

\section{EARNINGS IN STAGE 2}

After both participants make their bids, your earnings for the period are calculated. Regardless of who receives the reward, both participants will have to pay their bids. So your earnings will be calculated in the following way:

If you receive the reward:

Earnings in Stage $2=100-$ Your Bid

If you do not receive the reward:

Earnings in Stage $2=0-$ Your Bid

Remember you have already earned a $\$ 20.00$ participation fee (equivalent to 500 francs). In any period, you may receive either positive or negative earnings. At the end of the experiment we will randomly select four out of 30 periods for payment--two from the first 15 periods and two from the last 15 periods. We will sum the total earnings for these four periods and convert them to a U.S. dollar payment. If the summed earnings are negative, we will subtract them from your participation fee. If the summed earnings are positive, we will add them to your participation fee.

\section{What Does my Bid Mean?}

The more you bid, the more likely you are to receive the reward. The more the other person bids, the less likely you are to receive the reward. Specifically:

For each franc Person 1 bids Person 1 receives 8 lottery tickets

For each franc Person 2 bids Person 2 receives 2 lottery tickets

At the end of each period the computer draws randomly one ticket among all the tickets purchased by you and the other person. The owner of the winning ticket receives the reward of 100 francs. Each ticket has an equal chance of winning. So your chance of receiving the reward is given by the number of tickets you buy divided by the total number of tickets bought by you and the other person.

Chance of Receiving the Reward $=$

Your Total Lottery Tickets

Sum of Your and Other Person's Lottery Tickets

If both participants bid zero the reward is randomly assigned to one of the two participants.

\section{Determining Who Wins The Reward}


This is a hypothetical example used to illustrate how the computer determines who wins the reward of 100 francs. If Person 1 bids 20 francs and Person 2 bids 20 francs, then Person 1 receives 160 lottery tickets and Person 2 receives 40 lottery tickets. Then the computer randomly draws one lottery ticket out of $200(160+40)$. As you can see, Person 1 has a higher chance of receiving the reward, $0.80=160 / 200$. Person 2 has a $0.20=40 / 200$ chance of receiving the reward.

After both participants bid, the computer will make a random draw that will determine who receives the reward. Then the computer will calculate your period earnings based on your bid and whether you received the reward or not. At the end of each period, you will see:

1. Whether you chose to flip a coin and whether the other person chose to flip a coin,

2. If applicable, how much you bid and how much the other person bid,

3. Whether you received the reward or not, and

4. Your earnings for the period.

Once the outcome screen is displayed you should record your results for the period on your Personal Record Sheet under the appropriate heading. An example of the outcome screen is shown below.

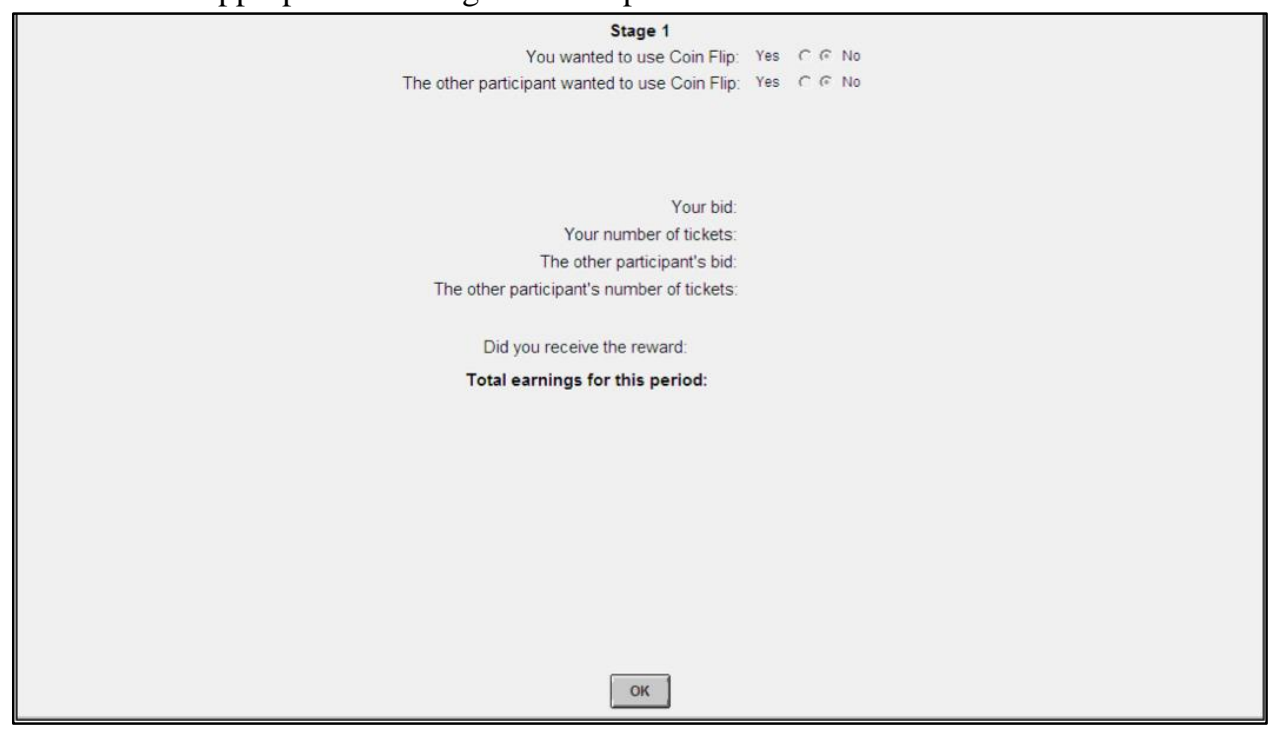

\section{IMPORTANT NOTES}

You will not be told which of the participants in this room are assigned to which two-person group. The group stays intact for 15 periods. At the end of 15 periods you will be randomly re-grouped with a different participant to form a new two-person group for another 15 periods. At the beginning of each period you will be told if you are Person 1 or Person 2. You will be Person 1 in half of the periods and Person 2 in half of the periods. You can never guarantee yourself the reward. If both participants choose to flip a computer coin in stage 1, then the reward is assigned randomly. If either person chooses not to flip a computer coin, then both participants proceed to stage 2 . In stage 2 , by increasing your bid you can increase your chance of receiving the reward.

\section{Quiz}

Before starting, we want you to answer some questions regarding the experiment to be sure you understand what will follow. After five minutes an experimenter will return to privately review your answers.

You will be Person 1 in how many of the periods?

You always have to bid more than zero (true or false)?

Your bid will be subtracted from your earnings (true or false)?

If both participants agree to the coin flip, what is the chance of Person 1 winning the reward?

Imagine Person 1 bids 1 franc and Person 2 bids 1 franc. What is the chance of Person 1 winning the reward? 
Imagine Person 1 bids 2 francs and Person 2 bids 8 francs. What is the chance of Person 1 winning the reward?

Imagine Person 1 bids 8 francs and Person 2 bids 16 francs. What is the chance of Person 1 winning the reward?

Imagine Person 1 bids 18 francs and Person 2 bids 24 francs. What is the chance of Person 1 winning the reward?

Imagine Person 1 bids 18 francs and Person 2 bids 72 francs. What is the chance of Person 1 winning the reward?

Imagine Person 1 bids 0 francs and Person 2 bids 1 franc. What is the chance of Person 1 winning the reward? 